\title{
Usefulness of Testing for Fecal Calprotectin in Pediatric Gastroenterology Clinical Practice
}

\author{
Eliza Lężyk-Ciemniak ${ }^{a} \quad$ Magdalena Tworkiewicz ${ }^{a}$ Dominika Wilczyńska ${ }^{a}$ \\ Anna Szaflarska-Popławska ${ }^{b}$ Aneta Krogulska ${ }^{a}$ \\ aDepartment of Pediatrics, Allergology and Gastroenterology Collegium Medicum Bydgoszcz, NCU Toruń, Bydgoszcz, \\ Poland; bepartment of Pediatric Endoscopy and Gastrointestinal Function Testing, NCU Toruń, Bydgoszcz, Poland
}

\section{Significance of the Study}

- This review focuses on the role of fecal calprotectin in the diagnosis of inflammatory bowel disease.

- It highlights the relevance of calprotectin in monitoring the effectiveness of therapy and postoperative relapses.

\section{Keywords}

Fecal calprotectin - Gastrointestinal tract disease · Inflammatory bowel disease $\cdot$ Pediatric gastroenterology

\begin{abstract}
Gastrointestinal tract symptoms such as abdominal pain, constipation, diarrhea, and fever are common reasons for which parents take children to the pediatrician. An increasing prevalence of chronic diseases of the gastrointestinal tract and a decrease in the median age of their onset indicate the need to search for new diagnostic methods for differentiating inflammatory bowel diseases (IBDs) from other gastrointestinal tract diseases. An example of a novel biomarker is fecal calprotectin ( $F C$ ), which is considered a noninvasive and useful marker of intestinal inflammation. This review summarizes currently available information on the use of FC in the diagnosis and monitoring of IBD in children. Additionally, it attempts to determine the course of action depending on the concentration of FC. Application of FC determination within the framework of primary medical care can decrease
\end{abstract}

karger@karger.com www.karger.com/mpp

Karger $\stackrel{\text { ' }}{5}$

GOPEN ACCESS
(C) 2020 The Author(s)

Published by S. Karger AG, Basel

This is an Open Access article licensed under the Creative Commons Attribution-NonCommercial-4.0 International License (CC BY-NC) (http://www.karger.com/Services/OpenAccessLicense), applicable to the online version of the article only. Usage and distribution for commercial purposes requires written permission. the number of children unnecessarily referred either to endoscopic or radiologic examination. There is a double advantage of calprotectin screening; for patients, it reduces delays in diagnosis and unnecessary exposure to endoscopy, and for doctors, it reduces pressure on endoscopy testing and facilitates decision-making. We emphasize the role of FC as a noninvasive marker, primarily in patients with IBD, in monitoring disease activity, predicting relapse, monitoring therapy efficacy, and monitoring postoperative relapses.

(c) 2020 The Author(s)
Published by S. Karger AG, Basel

\section{Introduction}

Inflammatory bowel disease (IBD) is a condition that affects mainly young people, both men and women. Most cases of the disease occur between 15 and 30 years of age $[1,2]$. Diagnosis of the disease in patients up to 18 years of age refers to $10-25 \%$ of IBD patients [1]. Henderson et al. [3] indicated the lowering of the mean age of onset of the disease during 2003-2008 as compared to the 1990s. 
Fig. 1. FC values depending on the age of patients $[11,13,14]$. FC, fecal calprotectin.

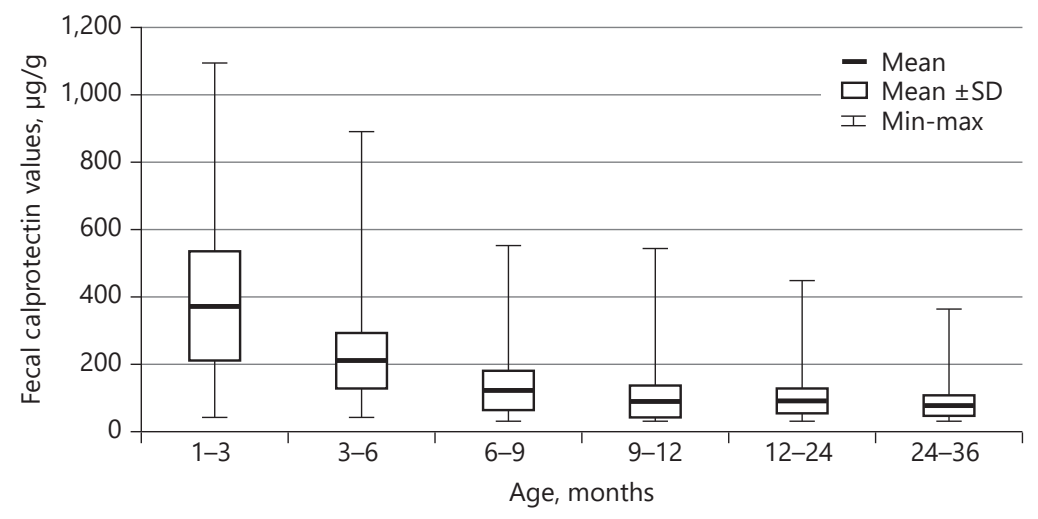

Due to the high prevalence of the disease and constant increase in the number of new IBD cases, improvement of diagnostic methods is of crucial importance $[3,4]$. IBD diagnostics makes use of laboratory tests such as C-reactive protein (CRP), erythrocyte sedimentation rate, and complete blood count, which are of low specificity $[5,6]$. The most efficient diagnostic method for IBD is endoscopy. The disadvantage of this method is its invasive character, in children the need for hospitalization, and the risk related to general anesthesia, which is of particular relevance in the pediatric population $[1,7]$. Due to the similarity of the clinical picture of IBD and other diseases such as functional gastrointestinal disorders or infectious diseases, for years, there has been a search for a marker that would help reduce the number of patients requiring endoscopic examination, would be less invasive, and would be relatively cheap [8]. The argument for the above are the data quoted by Van de Vijver et al. [9] who indicated that endoscopy failed to confirm the initial diagnosis in about $70 \%$ of patients with suspected IBD. An example of examination, thanks to which the accuracy of diagnosis can be increased, is the fecal calprotectin (FC) test. It is a noninvasive valuable marker of intestinal inflammation. Here, we provide a brief review of the usefulness of measurement of FC in the differential diagnosis of IBD and other gastrointestinal tract diseases with similar clinical symptoms, as well as in other diseases.

\section{Calprotectin}

Calprotectin is a protein discovered in 1980. It is present mainly in the cytoplasm of polymorphonuclear granulocytes, and also in monocytes and macrophages, and is related to inflammatory cytokine activity. It is antibacterial and antifungal. Physiologically, it can be detected in serum, amniotic fluid, saliva, and other secretions $[8,10$, 11]. An important property of calprotectin is protective immunity against pathogenic bacteria present in the intestines [8]. Initially, it was thought that FC does not lose its properties at room temperature even for up to 7 days, which would facilitate determination of this marker even in small medical units or outpatient clinics [12]. Recently, it was shown that the stability of calprotectin is better in samples stored at $4^{\circ} \mathrm{C}$. Low calprotectin values may result from poor sample storage [13].

Among other factors, calprotectin values depend also on patient's age (Fig. 1). In newborns, in the first week of life, calprotectin levels are the highest and decrease with age. According to Li et al. [13], in the first 3 months of age, mean FC equals $375.2 \mu \mathrm{g} / \mathrm{g}$, whereas in the $1-18$ months of age, it reduces to $174.3 \mu \mathrm{g} / \mathrm{g}$. Zhu et al. [11] reported that the mean FC level in the group of children aged 1-4 years equals $83.2 \mu \mathrm{g} / \mathrm{g}$, and its value decreases in the first years of life by about $15 \mu \mathrm{g} / \mathrm{g}$ per year. Roca et al. [14] suggest 3 different age-groups for evaluation of calprotectin; $910.3 \mu \mathrm{g} / \mathrm{g}$ and $7.4 \mathrm{mg} / \mathrm{kg}$ for $0-12$ months, $285.9 \mu \mathrm{g} / \mathrm{g}$ and $2.9 \mathrm{mg} / \mathrm{kg}$ for $1-4$ years, and $54.4 \mu \mathrm{g} / \mathrm{g}$ and $0.2 \mathrm{mg} / \mathrm{kg}$ for 4-12 years. Usually in the group of toddlers, the value of FC surpasses the level in adults, and it tends to decrease to the value observed in healthy adults by the fifth year of life [13]. Furthermore, a higher FC level was confirmed in infants than children aged $1-4$ years $[11,13]$. No differences were observed between males and females in concentration of FC [11]. When healthy individuals were studied, in $11 \%$ of children, calprotectin levels exceeded $>50 \mu \mathrm{g} / \mathrm{g}$; when FC was measured in the same group, the values were normal. Subjects in whom the level of FC 
Table 1. Accuracy of FC determination to distinguish organic from functional disorders in patients with gastrointestinal symptoms

\begin{tabular}{lcccc}
\hline Author [reference] & Patients, $n$ (age, years) & Sensitivity, $\%$ & Specificity, \% & Cutoff, $\mu \mathrm{g} / \mathrm{g}$ \\
\hline Berni Canani et al. [26] & $357(1-18)$ & 93 & 73 & 98 \\
Bunn et al. [28] & $22(1-18)$ & 100 & 86 & 50 \\
Carroccio et al. [29] & $24($ median 3, 5) & 70 & 93 & 50 \\
Fagerberg et al. [30] & $36(1-18)$ & 95 & 93 & 50 \\
Holtman et al. [31] & $114(4-18)$ & 95 & 95 & 50 \\
Bremner et al. [27] & $100(5-17)$ & 95 & 72 & 50 \\
\hline
\end{tabular}

FC, fecal calprotectin.

stayed high were eventually diagnosed with rectal inflammation [15]. There is no uniformly accepted value of FC in the healthy population. Beside age, sex, and the storage conditions, other studies are still ongoing to look for factors that can affect FC levels; these include drugs, diet, breastfeeding, and individual coefficient of variation in samples collected during the same day [16].

\section{Calprotectin and IBD}

\section{Calprotectin in the Diagnosis of IBD}

Increased concentrations of FC indicate an inflammatory process in the gastrointestinal tract. A high calprotectin value cannot be used for differential diagnosis in Crohn's disease (CD) and ulcerative colitis (UC) [8]. According to Henderson et al. [17], FC is characterized by high sensitivity but low specificity in children with suspected IBD. Being a first-degree relative of an IBD patient increases the likelihood of having elevated calprotectin value, despite the absence of evident gastrointestinal tract disease [18]. According to Olender et al. [19], a cutoff point of $100 \mu \mathrm{g} / \mathrm{g}$, instead of $50 \mu \mathrm{g} / \mathrm{g}$, has higher specificity in the diagnosis of IBD in the pediatric group [18]. Studies have demonstrated greater efficiency of calprotectin in diagnosis of IBD in children than in adults [19]. The presence of high levels of FC was evidenced in the course of IBD $[8,20]$. The first reports of this observation appeared in the 1990s; a positive correlation was observed between the calprotectin level and the intensity of inflammatory lesions in the intestines $[10,21,22]$. According to Pieczarkowski et al. [23], a calprotectin level $<100 \mu \mathrm{g} / \mathrm{g}$ concerns mainly patients with functional gastrointestinal disorder and children from the control group. It was found that even low values of FC, that is, $50 \mu \mathrm{g} / \mathrm{g}$, allow for the differentiation of organic versus functional gastro- intestinal tract diseases [10]. According to Tavabie et al. [10], calprotectin levels $<8 \mu \mathrm{g} / \mathrm{g}$ allow for being excluded from the IBD risk group. In the literature, the most frequent cutoff point suggesting the presence of organic intestinal disease is $>50 \mu \mathrm{g} / \mathrm{g}[10,24]$. However, when examining patients with symptoms suggesting the presence of irritable bowel syndrome (IBS), it was stated that in $1 / 3$ of patients, the value of calprotectin was $>50 \mu \mathrm{g} / \mathrm{g}$; eventually, $28 \%$ of them were diagnosed with organic intestinal disease, whereas in the group of patients with a calprotectin level $<50 \mu \mathrm{g} / \mathrm{g}$, organic intestinal disease was diagnosed in only $3 \%$ of patients $[10,12,24]$. Studies have been conducted on the determination of calprotectin levels that would prompt referral for endoscopy and allow for diagnosis of disease exacerbation in IBD patients [8, $16,20,25]$. Van de Vijver et al. [9] propose that a calprotectin cutoff point of $50 \mu \mathrm{g} / \mathrm{g}$ helps avoid endoscopy in $20 \%$ of children with gastrointestinal symptoms suggesting IBD, whereas with the increase in the cutoff point value to $>150 \mu \mathrm{g} / \mathrm{g}$, the number of patients referred for endoscopic examination in the group of people with IBD symptoms would decrease by an additional $7 \%[5,12]$. Similar results were obtained by Sipponen and Kolho [5]. In patients diagnosed with organic diseases, including IBD, calprotectin levels were reported to surpass $100 \mu \mathrm{g} / \mathrm{g}$ $[19,22]$. On the basis of this test, high specificity was stated when normal levels were assumed as being $<100 \mu \mathrm{g} / \mathrm{g}$ [22]. A meta-analysis suggested that assuming a calprotectin cutoff as $212 \mu \mathrm{g} / \mathrm{g}$ should increase the accuracy of referral for endoscopy [24]. The accuracy of FC to distinguish between organic and functional gastrointestinal disorders in children is presented in Table 1 [26-31]. A diagnostic algorithm for suspected IBD based on testing for FC is shown in Figure 2 [32]. According to Holtman et al. [31], the addition of FC to an evaluation of alarm symptoms can be an optimal strategy for stratifying chil- 


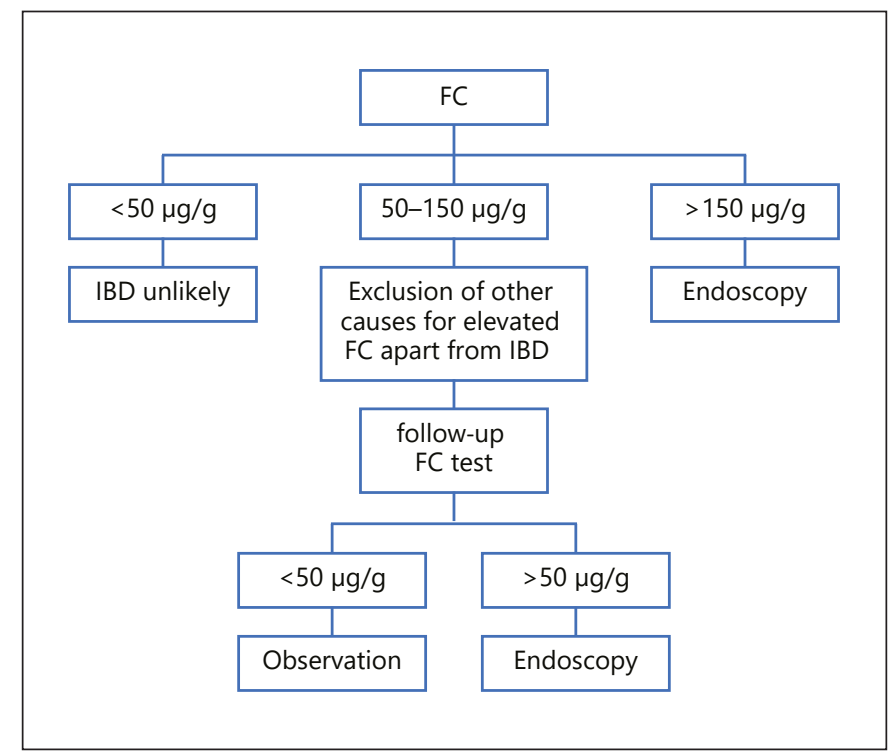

Fig. 2. Diagnostic algorithm for suspected IBD using FC test [ 32 in own modification]. IBD, inflammatory bowel disease; FC, fecal calprotectin.

dren identified by their general practitioner as being at risk for IBD. To date, however, there is insufficient evidence to recommend $\mathrm{FC}$ as a tool to guide decisions about referral for diagnostic workup of all children with chronic gastrointestinal symptoms seen in primary care [31].

\section{Calprotectin and Monitoring Disease Activity in IBD Patients}

Calprotectin reflects disease activity better in the course of UC in comparison to CD [17]. Calprotectin constitutes a diagnostic tool not only in IBD diagnosis but can also serve to monitor inflammatory lesions in the course of treatment. In the case of increased activity of the disease, relevant higher value of calprotectin is observed than patients with the disease in remission $[5,8]$. According to Paul et al. [33], in patients with CD, the value of FC $<250 \mu \mathrm{g} / \mathrm{g}$ confirms remission of mucosal inflammation.

Active inflammation confirmed by histopathological examination more frequently correlates with high concentrations of calprotectin than do clinical symptoms and serum inflammatory markers $[6,24]$. Calprotectin is a sensitive but nonspecific biomarker allowing for the assessment of disease activity in the course of UC, which is confirmed by histopathological and endoscopic examination [24]. In the diagnosis of disease exacerbation, measurement of calprotectin has higher sensitivity than the macroscopic picture of the large bowel. It makes it possible to diagnose disease progression in a simple and cheap manner, even before the symptoms of the disease appear [24]. A recent meta-analysis showed that the FC test is a simple, reliable, and noninvasive marker for predicting mucosal healing in UC patients [37]. Assumption of the cutoff point above which patients should be referred for endoscopic examination is of crucial importance [6]. Levels of calprotectin in 35\% of patients in the course of clinical remission are $<100 \mu \mathrm{g} / \mathrm{g}$, and in $13 \%$ of patients, the levels exceed $1,000 \mu \mathrm{g} / \mathrm{g}$ which indicates lack of mucosal remission. An increase in FC concentration is associated with a $53-83 \%$ risk of recurrence in the following 2-3 months [67]. In patients treated with infliximab, FC $>160 \mu \mathrm{g} / \mathrm{mg}$ was associated with a probability of recurrence higher than $60 \%$ over the next 8 weeks [67].

\section{Monitoring the Effectiveness of Therapy}

In clinical practice, "treat to target" is currently considered the most important strategy for therapy. The CALM study, a prospective, open, multicenter study, in Europe and Canada, evaluated 2 algorithms for managing $\mathrm{CD}$. It found that escalation of adalimumab treatment is based on levels of biomarkers such as calprotectin $>250$ $\mu \mathrm{g} / \mathrm{g}$ and $\mathrm{CRP}>5 \mathrm{mg} / \mathrm{L}$, and clinical assessment on the CD Activity Index (CDAI) scale gives better treatment efficacy in the form of endoscopically assessed intestinal healing than clinical assessment alone (reduction of CDAI $<70$ or CDAI $>200)$. In most of the patients, low FC $(<250 \mu \mathrm{g} / \mathrm{g})$ and negative CRP $(<5 \mathrm{mg} / \mathrm{L})$ meant healing of the mucosa and deep remission confirmed by endoscopic examination [34]. It seems that inclusion of calprotectin in the CDAI scale may increase the value of commonly used questionnaires assessing disease activity [6]. Low levels of FC in the course of maintenance treatment increase the likelihood of remaining in clinical remission for another year [36]. Monitoring this intestinal marker in IBD as early as in the initial phase of therapy (e.g., after steroid administration) may objectively indicate a chance for clinical improvement [8]. Molander et al. [38] confirmed that $\mathrm{FC}<100 \mu \mathrm{g} / \mathrm{g}$ in patients with IBD after the induction phase of infliximab treatment is a good prognostic factor for clinical remission.

The STORI study consisted of serial measurements of FC in patients with CD in clinical remission after discontinuation of infliximab; it showed that levels of FC increased 4-6 months earlier in patients with relapsed disease [68]. The most important goal in the treatment of 
IBD patients is to achieve histopathological remission; however, clinical remission does not correlate with endoscopic remission. Many studies show that changes in calprotectin levels may precede both clinical symptoms and endoscopic changes. This was confirmed in pediatric patients with UC; high values (mean cutoff point $285 \mu \mathrm{g} / \mathrm{g}$ ) of FC correlated with exacerbation of the disease in endoscopic studies, despite no clinical progression $[69,70]$. Unfortunately, FC correlates worse with lesions in the small intestine, and thus, it cannot replace capsule endoscopy [71].

\section{Monitoring of Postoperative Relapses}

Although the role of FC in the early detection of postoperative relapses is still not established, several studies suggest that measurement of FC may help avoid unnecessary endoscopy and facilitate earlier diagnosis [72, 73]. In CD patients who underwent surgical resection of the intestine, calprotectin levels normalized within 2 months after surgery [35].

Scarpa et al. [35] opine that measurement of calprotectin is of better value than ultrasound examination to monitor disease exacerbation and postoperative recurrence of the disease. The optimum time limit for calprotectin determination after surgical resection is 12 weeks.

The rate of postoperative relapses in patients with high levels of FC compared to those with low levels was 75-9\% [73]. In a study on both adult and pediatric patients, it was found that $\mathrm{FC}>139 \mu \mathrm{g} / \mathrm{g}$ during endoscopy or an increase of $79 \mu \mathrm{g} / \mathrm{g}$ in relation to the first values after surgery suggested endoscopic recurrence, while FC $>101 \mu \mathrm{g} / \mathrm{g}$ or increase of $21 \mu \mathrm{g} / \mathrm{g}$ indicated a histological recurrence [73].

\section{Calprotectin and Location of IBD}

The diagnostic value of FC is the highest in the case of inflammatory lesions in the colon but is still relevant in the case of lesions in the small intestine $[6,39]$. Determination of calprotectin is also useful for assessing the extent of inflammatory lesions in the course of IBD, which is highest in the colon [6] and lowest in lesions restricted to the small intestine $[6,31]$. The highest relevance of calprotectin was indicated in a group of patients whose lesions simultaneously involved the colon and small intestine [31]. Locating lesions in the small intestine in the course of $\mathrm{CD}$ is the biggest diagnostic challenge. The relevance of calprotectin determination in patients with this
Table 2. Causes of elevated FC other than IBD [46-73]

\begin{tabular}{ll}
\hline Type of the causes & Diseases \\
\hline Inflammatory/infectious & Giardia lamblia \\
& Clostridium difficile \\
& Bacterial factors \\
& Viral factors \\
& HIV \\
Untreated celiac disease & Diverticulosis \\
& Microscopic colitis \\
& SIBO \\
& Pancreatitis \\
& Pouchitis \\
& Juvenile polyposis \\
& Pancreatic cancer* \\
& Intestinal polyposis \\
& Colorectal cancer* \\
\hline Neoplasms & NSAIDs \\
& PPIs \\
\hline Iatrogenic & Radiotherapy* \\
& Graft rejection following \\
Intestinal transplant \\
Untreated food allergy \\
Cystic fibrosis \\
Age $<5$ years \\
Liver cirrhosis \\
Gastroesophageal reflux disease \\
Immune deficiency \\
Protein-losing enteropathy \\
\hline \\
\end{tabular}

PPIs, proton pump inhibitors; HIV, human immunodeficiency virus; NSAIDs, nonsteroidal anti-inflammatory drugs; IBD, inflammatory bowel disease; FC, fecal calprotectin; SIBO, small intestinal bacterial outgrowth. ${ }^{*}$ Very rarely seen in children.

location of the disease is lower; however, it should not be the cause for ceasing to perform this examination [6]; irrespective of location of inflammatory lesions, calprotectin helps in the assessment of disease activity.

\section{Calprotectin and Other Diseases}

Besides IBD, an increased level of FC may be caused by diseases such as inflammatory/infectious diseases, cancers, iatrogenic causes, and others (Table 2) [40-64].

\section{Inflammatory/Infectious Diseases}

Determination of FC can be a relevant tool for differentiating the etiology of acute diarrhea in children, which is of crucial importance in consideration of its frequent 
prevalence in the pediatric population. However, increased levels of FC were found in children with bacterial and viral diarrhea, with higher levels FC in the course of bacterial, rather than viral, diarrhea [41]. Mean levels of FC levels were $89-95 \mu \mathrm{g} / \mathrm{g}$ in patients with viral infection, $754 \mu \mathrm{g} / \mathrm{g}$ in children with bacterial diarrhea, and $43 \mu \mathrm{g} / \mathrm{g}$ in the control group. Abnormal levels of both CRP and FC indicated a bacterial etiology of diarrhea [40].

Levels of FC were found to be lower in patients with mild Clostridium difficile infection than that in those with severe infection and those in the control group. Moreover, Kim et al. [42] proposed the use of FC levels as a predictive marker for assessing the severity of $C$. difficile infection.

\section{Celiac Disease}

Celiac disease is another example of a disease in the course of which abnormal levels of calprotectin are observed. The value is dependent on the stage of the disease [43], with the highest levels found in newly diagnosed celiac disease and decreased levels observed after glutenfree diet application; however, this was not substantiated in another study [44].

\section{Diverticular Disease}

Tursi et al. [46] reported high concentrations of FC in patients with diverticular disease compared to healthy individuals and patients with IBS. Levels of FC also normalized after treatment with mesalazine and rifaximin [46]. Additionally, levels $>60 \mu \mathrm{g} / \mathrm{g}$ were reported to be correlated with acute complications of diverticular disease [47].

\section{Microscopic Colitis}

A slight elevation in levels of calprotectin, indicating an inflammatory response, was observed in patients with active microscopic colitis, compared with the remission and IBS groups; the usefulness of FC as a biomarker of microscopic colitis is not clear [61]. Fifteen of 78 patients with chronic diarrhea were found to have microscopic colitis, regardless of FC levels; they concluded that colonic biopsy is important for making specific diagnosis [48]. Additionally, Batista et al. [49] reported a lack of association between microscopic colitis and calprotectin levels.

\section{Small Intestinal Bacterial Overgrowth}

The potential role of FC as a marker of subclinical intestinal inflammation has also been studied in subjects with small intestinal bacterial outgrowth (SIBO). Median levels of FC were shown to be normal in children with SIBO and healthy children [50]. Fundarò et al. [51] obtained similar results and suggested that subclinical intes- tinal inflammation involving neutrophils does not occur in patients with proliferation of bacteria in the small bowel; thus, the presence of high levels of FC in children affected by SIBO may not be caused by bacterial overgrowth itself.

\section{Pouchitis}

Patients with pouchitis have a higher level of FC than healthy subjects [52].

\section{Neoplasms}

\section{Juvenile Polyposis}

High FC values may occur in the course of juvenile polyposis which may make it difficult to differentiate from IBD. During the course of juvenile polyposis syndrome, the calprotectin levels can be high, even as high as $1,075 \mu \mathrm{g} / \mathrm{g}$, but still lower in comparison to active IBD, where it can go as high as $2,189 \mu \mathrm{g} / \mathrm{g}$ in CD and 3,590 $\mu \mathrm{g} / \mathrm{g}$ in UC [19]. Determination of FC is not a useful test in the diagnosis of colon cancer, adenomatous polyps, and diverticulitis, despite the fact that levels are higher in these diseases than in healthy individuals $[12,47]$.

\section{Graft versus Host Disease}

A study of 59 patients with graft versus host disease (GVHD) showed that the FClevel in patients with gastrointestinal-GVHD was $500 \mu \mathrm{g} / \mathrm{kg}$, while in patients without gastrointestinal-GVHD, it was $95 \mu \mathrm{g} / \mathrm{kg}$. Sensitivity and specificity were 100 and $81.8 \%$, respectively, with a cutoff point of $160 \mu \mathrm{g} / \mathrm{kg}$ [45].

\section{Radiotherapy}

In the study of 59 patients after therapeutic pelvic radiotherapy, the mean FC level was $62.9 \mu \mathrm{g} / \mathrm{g}$ [60]. Studies also show that high FC levels in patients with liver cirrhosis, gastroesophageal reflux disease, and cystic fibrosis, after intestinal transplant [61-64].

\section{latrogenic Causes}

\section{Nonsteroidal Anti-Inflammatory Drugs}

Nonsteroidal anti-inflammatory drugs (NSAIDs) have been shown to induce enteropathy at different levels of the gastrointestinal tract. Studies demonstrated that the effect of NSAIDs on FC might be seen as a few days after the initiation of these medications [56]. It is well known that the use of NSAIDs is associated with a moderate increase in levels of FC [57]. 


\section{Proton Pump Inhibitors}

The use of proton pump inhibitors (PPIs) is associated with higher levels of FC [58]. Lundgren et al. [59] demonstrated that increased age and the use of NSAIDs, acetylsalicylic acid, and PPIs were associated with increased levels of FC in patients with normal colonoscopy. They suggest that the use of these drugs should be considered in the interpretation of FC tests in clinical practice [59].

\section{Systemic Diseases}

Ankylosing spondylitis (AS) and IBD are known to share some clinicopathological features. A prospective study of 39 patients with AS and healthy controls showed a difference in the median levels of FC in patients with AS compared to healthy controls [53]. Similarly, Simioni et al. [54] have shown higher FC levels in patients with ankylosing spondylitis. A study on 81 systemic sclerosis patients showed that $76 \%$ of the patients had a mean FC level of $174 \mu \mathrm{g} / \mathrm{g}$, with a cutoff of $50 \mu \mathrm{g} / \mathrm{g}$ [55].

\section{Conclusions}

FC is a promising parameter allowing for differentiation between organic and functional gastrointestinal tract diseases. High levels of FC increase the probability of organic gastrointestinal disease, especially IBD; however, measurement of $\mathrm{FC}$ does not allow for differentiation of CD from UC. FC is not a specific marker of IBD, but levels of FC are highest during active disease. One of the main problems is the unification of the cutoff point for "negative" and "positive" results and establishing the calprotectin concentration at diagnosis and then during follow-up. What is extremely difficult is the interpretation of results which are higher than the upper normal limit, but lower than the one typical for IBD. Therefore, before referral for this test, it is important to consider what procedure should be followed in the case of a positive or negative result. If the procedure is the same both in the case of a positive and a negative result, then there is no point in performing the test. FC can be also a useful diagnostic tool in the assessment of response to treatment, monitoring disease activity, and treatment optimization in children with IBD. The determination of FC may help in the assessment of the risk of the disease recurring after surgical treatment. There are currently no recommendations regarding the frequency of monitoring calprotectin levels. Calprotectin may be useful in establishing the diagno- sis of IBD, as well as for monitoring the disease and choosing the treatment [65]. Certain limitations exist with the assessment of calprotectin. These include the elevated levels of FC in diseases, other than IBD (gastrointestinal as well extraintestinal), and the physiologically higher levels of calprotectin observed in infants and toddlers.

Calprotectin and lactoferrin have generally been well described as fecal biomarkers in IBD. Other less known fecal biomarkers include M2 pyruvate kinase, osteoprotegerin, myeloperoxidase, HMGB1, 3-like chitinase 1, defensins, matrix metalloproteinases, and human nucleic acid. Most of them require further extensive evaluation and research [66]. Application of FC determination within the framework of primary medical care could help decrease the number of children unnecessarily referred for endoscopy and magnetic resonance imaging.

\section{Acknowledgement}

No financial support was received for preparing this review.

\section{Statement of Ethics}

The content of the document is consistent with the scope of the Helsinki Declaration, EU directives, and uniform requirements for biomedical journals.

\section{Conflict of Interest Statement}

The authors declare that they have no conflicts of interest.

\section{Author Contributions}

E.E.-C., M.T., and D.W.: collection of data and literature and drafting of the manuscript; A.S.-P. and A.K.: collection of data and literature, drafting of the manuscript, and preparation of the final version. All authors: review of the final version of the manuscript.

\section{References $\quad 1$ Levine A, Koletzko S, Turner D, Escher JC, Cucchiara S, de Ridder L, et al. ESPGHAN re- vised porto criteria for the diagnosis of in- flammatory bowel disease in children and ad- olescents. J Pediatr Gastroenterol Nutr. 2014 58(6):795-806. \\ 2 Walsham N, Sherwood R. Fecal calprotectin in inflammatory bowel disease. Clinical and experimental gastroenterology. Clin Exp Gas- troenterol. 2016;9:21-9. \\ 3 Henderson P, Hansen R, Cameron FL, Gera- simidis $\mathrm{K}$, Rogers $\mathrm{P}$, Bisset WM, et al. Rising incidence of pediatric inflammatory bowel disease in Scotland. Inflamm Bowel Dis. 2012; 18(6):999-1005.}


4 Leone V, Chang E, Devkota S. Diet, microbes and host genetics: the perfect storm in inflammatory bowel diseases. J Gastroenterol. 2013;48(3):315-21.

5 Sipponen T, Kolho K. Fecal calprotectin in diagnosis and clinical assessment of inflammatory bowel disease. Scand J Gastroenterol. 2015;50(1):74-80.

6 Mumolo M, Bertani L, Ceccarelli L, Laino G, Di Fluri G, Albano E, et al. From bench bedside: fecal calprotectin in inflammatory bowel diseases clinical setting. World J Gastroenterol. 2018;24(33):3681-94.

7 Magro F, Gionchetti P, Eliakim R, Ardizzone A, Barreiro de A, costa M, et al. European Crohns and Colitis Ogranisation (ECCO) Third European Evidence-based Consensus on Diagnosis and Management of Ulcerative Colitis. Part 1: definitions, diagnosis, extraintestinal manifestations, pregnancy, cancer surveillance, surgery, and ileo-anal pouch disorders. J Crohns Colitis. 2017;11(6):649-70.

8 Pathirana WGW, Chubb SP, Gillett MJ, Vasikaran SD. Faecal calprotectin. Clin Biochem Rev. 2018;39(3):77-90.

9 Van de Vijver E, Schreuder AB, Cnossen WR, Muller Kobold AC, van Rheenen PF. Safely ruling out inflammatory bowel disease in children and teenagers without referral for endoscopy. Arch Dis Child. 2012;97(12): $1014-8$.

10 Tavabie OD, Hughes SA, Loganayagam A The role of faecal calprotectin in the differentiation of organic from functional bowel disorders. Br J Gen Pract. 2014;64(628):595-6.

11 Zhu Q, Li F, Wang J, Shen L, Sheng X. Fecal calprotectin in healthy children aged 1-4 years. PLoS One. 2016;11(3):e0150725.

12 Burri E, Beglinger C. The use of fecal calprotectin as a biomarker in gastrointestinal disease. Expert Rev Gastroenterol Hepatol. 2014; 8(2):197-210.

13 Li F, Ma J, Geng S, Wang J, Liu J, Zhang J, et al. Fecal calprotectin concentrations in healthy children aged 1-18 months. PLoS One. 2015;10(3): $\mathrm{e} 0119574$.

14 Roca M, Rodriguez Varela A, Donat E, Cano F, Hervas D, Armisen A, et al. Fecal calprotectin and eosinophil-derived neurotoxin in healthy children between 0 and 12 years. J Pediatr Gastroenterol Nutr. 2017;65(4):394-8.

15 Knyazev OV, Kagramanova AV, Korneeva IA, Noskova KK, Belousov SV, Parfenov AI. The use of fecal calprotectin in monitoring activity of inflammatory bowel diseases. Ter Arkh. 2019;91(4):53-61.

16 Angelo DF, Ch F, Frossard JL. Calprotectin in daily practice: where do we stand in 2017. Digestion. 2017;95:293-301.

17 Henderson P, Anderson NH, Wilson DC. The diagnostic accuracy of fecal calprotectin during the investigation of suspected pediatric inflammatory bowel disease: a systematic review and meta-analysis. Am J Gastroenterol. 2014;109(5):637-45.

18 Gisbert JP, McNicholl AG. Questions and answers on the role of faecal calprotectin as a biological marker in inflammatory bowel disease. Dig Liver Dis. 2009;41(1):56-66.

19 Olender K, Bergmann K, OdrowążSypniewska G. Fecal calprotectin as an inflammatory marker in inflammatory bowel disease. Diagn Lab. 2012;48:433-9.

20 Zijlstra M, Pluimakers V, Nikkels P, Wolters V, Houwen R. Elevated faecal calprotectin does not differentiate between inflammatory bowel disease and a juvenile polyp. J Pediatr Gastroenterol Nutr. 2016;62(2):e22-3.

21 Hoekman DR, Diederen K, Koot BG, Tabbers MM, Kindermann A, Benninga MA, et al. Relationship of clinical symptoms with biomarkers of inflammation in pediatric inflammatory bowel disease. Eur J Pediatr. 2016; 175(10):1335-42.

22 Copova I, Hradsky O, Zarubova K, Gonsorcikova L, Potuznikova K, Lerchova T, et al. Fecal calprotectin is not a clinically useful marker for the prediction of the early nonresponse to exclusive enteral nutrition in pediatric patients with Crohn disease. Eur J Pediatr. 2018;177(11):1685-93.

23 Pieczarkowski S, Kowalska-Duplaga K, Kwinta P, Tomasik P, Wędrychowicz A, Fyderek K. Diagnostic value of fecal calprotectin (S100 A8/A9) test in hildren with chronic abdominal pain. Gastroenterol Res Pract. 2016; 7:1-7.

24 Degraeuwe PL, Beld MP, Ashorn M, Canani RB, Day AS, Diamanti A, et al. Faecal calprotectin in suspected paediatric inflammatory bowel disease. J Pediatr Gastroenterol Nutr. 2015;60(3):339-46.

25 Akobeng AK. Clinical usefulness of the faecal calprotectin test in suspected paediatric inflammatory bowel disease. Acta Paediatr. 2018;107(11):2019-23.

26 Berni Canani R, Rapacciuolo L, Romano MT, Tanturri de Horatio L, Terrin G, Manguso F, et al. Diagnostic value of faecal calprotectin in paediatric gastroenterology clinical practice. Dig Liver Dis. 2004;36(7):467-70.

27 Bremner A, Roked S, Robinson R, Phillips I, Beattie M. Faecal calprotectin in children with chronic gastrointestinal symptoms. Acta Paediatr. 2005 Dec;94(12):1855-8.

28 Bunn SK, Bisser WM, Main MJ, Gray ES, Olson $\mathrm{S}$, Golden BE, et al. Fecal calprotectin: validation as a non-invasive measure of bowel inflammation in childhood inflammatory bowel disease. J Pediatr Gastroenterol Nutr. $2001 \mathrm{Jul} ; 33(1): 14-22$

29 Carroccio A, Iacono G, Cottone M, di Prima L, Cartabellotta F, Cavataio F, et al. Diagnostic accuracy of fecal calprotectin assay in distinguishing organic causes of chronic diarrhea from irritable bowel syndrome: a prospective study in adults and children. Clin Chem. 2003;49(6 Pt 1):861-7.

30 Fagerberg UL, Lööf L, Lindholm J, Hansson LO, Finkel Y, et al. Fecal calprotectin: a quantitative marker of colonic inflammation in children with inflammatory bowel disease. J Pediatr Gastroenterol Nutr. 2007 Oct;45(4): 414-20.
31 Holtman GA, Lisman-van Leeuwen Y, Kollen BJ, Norbruis OF, Escher JC, Kindermann A, et al. Diagnostic accuracy of fecal calprotectin for pediatric inflammatory bowel disease in primary care: a prospective cohort study. Ann Fam Med. 2016 Sep;14(5):437-45.

32 Sherwood RA. Faecal markers of gastrointestinal inflammation. J Clin Pathol. 2012 Nov; 65(11):981-5.

33 Paul S, Del Tedesco E, Marotte H, RinaudoGaujous M, Moreau A, Phelip JM, et al. Therapeutic drug monitoring of infliximab and mucosal healing in inflammatory bowel disease: a prospective study. Inflamm Bowel Dis. 2013;19(12):2568-76.

34 Colombel JF, Panaccione R, Bossuyt P, Lukas $\mathrm{M}$, Baert F, Vanasek T, et al. Effect of tight control management on Crohn's disease (CALM): a multicentre, randomised, controlled phase 3 trial. Lancet. 2017 Dec;390:2779-89.

35 Scarpa M, D’Incà R, Basso D, Ruffolo C, Polese L, Bertin E, et al. Fecal lactoferrin and calprotectin after ileocolonic resection for Crohn's disease. Dis Colon Rectum. 2007; 50(6):861-9.

36 Sipponen T, Kolho KL. Faecal calprotectin in children with clinically quiescent inflammatory bowel disease. Scand J Gastroenterol. 2010;45(7-8):872-7.

37 Dai C, Jiang M, Sun M, Cao Q. Fecal immunchemical test for predicting mucosal healing in ulcerative colitis patients: a systematic review and meta-analysis. J Gastroenterol Hepatol. 2018;33:980-97.

38 Molander P, af Björkesten CG, Mustonen H, Haapamäki J, Vauhkonen M, Kolho KL, et al. Fecal calprotectin concentration predicts outcome in inflammatory bowel disease after induction therapy with TNF $\alpha$ blocking agents. Inflamm Bowel Dis. 2012;18(11):2011-7.

39 Stawczyk-Eder K, Eder P, Lykowska-Szuber L, Krela -Kazmierczak I, Klimczak K, Szymczak $\mathrm{A}$, et al. Is fecal calprotectin equally useful in all Crohn's disease locations? A prospective, comparative study. Arch Med Sci. 2015;11:353-6.

40 Chen CC, Huang JL, Chang CJ, Kong MS. Fecal calprotectin as a correlative marker in clinical severity of infectious diarrhea and usefulness in evaluating bacterial or viral pathogens in children. J Pediatr Gastroenterol Nutr. 2012;55(5):541-7.

41 Sýkora J, Siala K, Huml M, Varvařovská J, Schwarz I, Pomahačová R. Evaluation of faecal calprotectin as a valuable non-invasive marker in distinguishing gut pathogens in young children with acute gastroenteritis. Acta Paediatr. 2010;99(9):1389-95.

42 Kim J, Kim H, Oh HJ, Kim HS, Hwang YJ, Yong D, et al. Fecal calprotectin level reflects the severity of clostridium difficile infection. Ann Lab Med. 2017;37(1):53-7.

43 Balamtekın N, Baysoy G, Uslu N, Orhan D, Akçören Z, Özen H, et al. Fecal calprotectin concentration is increased in children with celiac disease: relation with histopathological findings. Turk J Gastroenterol. 2012;23(5): 503-8. 
44 Capone P, Rispo A, Imperatore N, Caporaso $\mathrm{N}$, Tortora R. Fecal calprotectin in coeliac disease. World J Gastroenterol. 2014;20(2):6112.

45 Chiusolo P, Metafuni E, Giammarco S, Bellesi S, Piccirillo N, Fanali C, et al. Role of fecal calprotectin as biomarker of gastrointestinal GVHD after allogeneic stem cell transplantation. Blood. 2012;120(22):4443-4.

46 Tursi A, Brandimarte G, Elisei W, Inchingolo CD, Danese S, Aiello F. Fecal calprotectin in colonic diverticular disease: a case control study. Int J Colorectal Dis. 2009 Jan;24(1):4955.

47 Tursi A. Biomarkers in diverticular diseases of the colon. Dig Dis. 2012;30(1):12-8.

48 Larsson JK, Sjoberg K, Vigren L, Benoni C, Toth E, Olesen M. Chronic non-bloody diarrhea: a prospective study in Malmo, Sweden, with focus on microscopic colitis. BMC Res Notes. 2014;7:236.

49 Batista L, Ruiz L, Ferrer C, Zabana Y, Aceituno M, Arau B, et al. Usefulness of fecal calprotectin as a biomarker of microscopic colitis in a cohort of patients with chronic watery diarrhoea of functional characteristics. Dig Liver Dis. 2019;51(12):1646-51.

50 Montalto M, Santoro L, Dalvai S, Curigliano V, D'Onofrio F, Scarpellini E, et al. Fecal calprotectin concentrations in patients with small intestinal bacterial overgrowth. Dig Dis. 2008;26(2):183-6.

51 Fundarò C, Fantacci C, Ansuini V, Giorgio V, Filoni S, Barbaro F, et al. Fecal calprotectin concentration in children affected by SIBO Eur Rev Med Pharmacol Sci. 2011 Nov; 15(11):1328-35.

52 Shepherd NA, Jass JR, Duval I, Moskowitz RL Nicholls RJ, Morson BC. Restorative proctocolectomy with ileal reservoir: pathological and histochemical study of mucosal biopsy specimens. J Clin Pathol. 1987;40(6):601-7.

53 Matzkies FG, Targan SR, Berel D, Landers CJ, Reveille JD, McGovern DP, et al. Markers of intestinal inflammation in patients with ankylosing spondylitis: a pilot study. Arthritis Res Ther. 2012;14(6):R261.
54 Simioni J, Skare TL, Campos APB, Kotze L, Messias-Reason I, Ioshii SO, et al. Fecal calprotectin, gut inflammation and spondyloarthritis. Arch Med Res. 2019 Jan;50(1):41-6.

55 Andreasson K, Scheja A, Saxne T, Ohlsson B. Hesselstrand B Fecal calprotectin: a biomarker of gastrointestinal disease in systemic sclerosis. J Intern Med. 2011;270:50-7.

56 Meling TR, Aabakken L, Røseth A, Osnes M. Faecal calprotectin shedding after short-term treatment with non-steroidal anti-inflammatory drugs. Scand J Gastroenterol. 1996;31(4): $339-44$.

57 Rendek Z, Falk M, Grodzinsky E, Wahlin K, Kechagias S, Svernlöv R, et al. Effect of oral diclofenac intake on faecal calprotectin. Scand J Gastroenterol. 2016;51(1):28-32.

58 Poullis A, Foster R, Mendall MA, Shreeve D, Wiener K. Proton pump inhibitors are associated with elevation of faecal calprotectin and may affect specificity. Eur I Gastroenterol Hepatol. 2003;15(5):573-4.

59 Lundgren D, Eklöf V, Palmqvist R, Hultdin J, Karling P. Proton pump inhibitor use is associated with elevated faecal calprotectin levels. A cross-sectional study on subjects referred for colonoscopy. Scand J Gastroenterol. 2019 Feb;54(2):152-7.

60 Wedlake L, McGough C, Hackett C, Thomas $\mathrm{K}$, Blake $\mathrm{P}$, Harrington $\mathrm{K}$, et al. Can biological markers act as non-invasive, sensitive indicators of radiation-induced effects in the gastrointestinal mucosa? Aliment Pharmacol Ther. 2008;27(10):980-7.

61 Garcia -Tsao G, Wiest R. Gut microflora in the pathogenesis of the complications of cirrhosis. Best Pract Res Clin Gastroenterol. 2004; 18:353-72.

62 Smyth RL, Croft NM, O’Hea U, Marshall TG, Ferguson A. Intestinal inflammation in cystic fibrosis. Arch Dis Child. 2000;82(5):394-9.

63 Mercer DF, Vargas L, Sun Y, Moreno AM, Grant WJ, Botha JF, et al. Stool calprotectin monitoring after small intestine transplantation. Transplantation. 2011;91(10):1166-71.

64 Chiusolo P, Metafuni E, Giammarco S, Bellesi S, Piccirillo N, Fanali C, et al. Role of fecal calprotectin as biomarker of gastrointestinal graft-versus-host disease. Blood. 2012;119: 5909-17.
65 Louis E, Dotan I, Ghosh S, Mlynarsky L, Reenaers $\mathrm{C}$, Schreiber S. Optimising the inflammatory bowel disease unit to improve quality of care: expert recommendations. J Crohns Colitis. 2015;9(8):685-91.

66 Duvoisin G, Lopez RN, Day AS, Lemberg DA, Gearry RB, Leach ST. Novel biomarkers and the future potential of biomarkers in inflammatory bowel disease. Mediators Inflamm. 2017;2017:1936315.

67 Heida A, Park KT, van Rheenen PF. Clinical utility of fecal calprotectin monitoring in asymptomatic patients with inflammatory bowel disease: a systematic review and practical guide. Inflamm Bowel Dis. 2017 Jun;23(6): 894-902.

68 Suray N, Salleron J, Vernier-Massouille G, Grimaud J, Bouhnik Y, Laharie D, et al. Close monitoring of CRP and fecal calprotectin is able to predict clinical relapse in patients with Crohn's disease in remission after infliximab withdrawal: a sub-analysis of the STORI study. ACAAI Gastroenterol. 2012;142.

69 Shentova R, Baycheva M, Hadjiiski P, Kofinova $D$, Yaneva P. Role of faecal calprotectin as a predictor of endoscopic activity in paediatric patients with ulcerative colitis. Gastroenterol Hepatol. 2020 Jan;43(1):57-61.

70 Bertani L, Mumolo M, Tapete G, Albano E, Baiano G, et al. Fecal calprotectin current and future perspectives for inflammatory bowel disease treatment. Eur J Gastroenterol Hepatol. 2020 Sep;32(9):1091-8.

71 Vernia F, Di Ruscio M, Stefanelli G, Viscido A, Frieri G, Latella G. Is fecal calprotectin an accurate marker in the management of Crohn's disease? J Gastroenterol Hepatol. 2020 Jan;35(3):390-400.

72 Planella E, Manosa M, Cabre E, Marin L, Gordillo I, et al. Fecal calprotectin levels are closely correlated with the absence of relevant mucosal lesions in postoperative Crohn's disease. Inflamm Bowel Dis. 2016 Dec;22(12):287985.

73 Hukkinen M, Pakarinen MP, Merras-Salmio L, Koivusalo A, Rintala R, Kolho KL. Fecal calprotectin in the prediction of postoperative recurrence of Crohn's disease in children and adolescents. J Pediatr Surg. 2016 Sep;51(9): 1467-72. 